\title{
Bankers or Brokers? For Favored Firms, VCs Invest More than Dollars
}

\author{
Emily Pahnke (University of Washington)
}

KEYWORDS: Entrepreneurship, Information Technology, Venture Capital, financing.

\section{By Emily Pahnke, Ji Youn (Rose) Kim, Michael Howard and Warren Boeker}

Venture capitalists bankroll invention, but is signing checks the only contribution they make to the world of innovation? Our research suggests (https://journals.aom.org/doi/abs/10.5465/ambpp.2013. 10478abstract) the answer is no.

By coordinating knowledge among firms in their portfolio networks, VCs actually contribute to technological progress and the growth of industries. In turn, the better VCs are at selectively directing firms in their portfolios to specific knowledge, the better their overall portfolios may perform. For VCs, that suggests that failing to optimize an investment portfolio can be costly. For startups, it shows there are risks associated with VC investment for those not among the favorites in a portfolio.

\section{Our Research}

Our research focused on VC-backed minimally invasive surgical (MIS) device startups in the U.S. from 1986 to 2007. We looked at how VCs construct their portfolios of firms, the structure of knowledge in those portfolios, how knowledge flowed between the portfolios' firms, and how those knowledge flows ultimately benefited the VCs. Markers of success were new product introductions and successful exit events, such as initial public offerings or acquisitions of firms. We interviewed 30 MIS device experts in various fields, including venture capitalists, entrepreneurs, regulators, engineers, surgeons, medical professors and consultants. We gathered data from industry intelligence firms and trade organizations, and we utilized keyword searches to find individual startups. We then identified each VC that invested in those firms, then excluded any that had only one MIS firm in their portfolio. That left us with 159 VCs.

\section{Findings}

Our study showed that VC portfolios with more breadth of knowledge are more likely to be successful, but only to a point: There are diminishing returns as VCs exploit too wide a range of technological areas. Portfolios more narrowly focused on a single technological area, such as cardiac stents, were found to perform better, likely because they could more effectively reconfigure knowledge to make a greater impact. Likewise, the more strategic VCs were about distributing knowledge, the better their overall portfolios performed: VCs who unevenly direct both knowledge and resources to their portfolio's most promising firms are more successful. Such direction could include pointing them to technical experts, directing their attention to emerging technologies, and helping them hire seasoned professional managers. VCs who spread attention evenly, meanwhile, effectively subsidize failing efforts at the expense of more promising ones.

This correlation between the strategic transfer of knowledge and the success of a portfolio means that while VCs do not directly participate in the development of technology, their financial interests lead them to channel their knowledge in ways that result in successful product launches and exit events for entrepreneurs. And as VCs share knowledge, they can also increase the competitive intensity of industries in which they are heavily invested. Thus VCs may play an important and under-studied role in shaping the trajectory and development of new industries.

\section{Suggestions for Further Study}

The rapidly changing nature of the high-tech industry makes awareness of and adaptability to new ideas crucial to success. The chief limitation of our study, then, may be its applicability to settings in which knowledge sharing is less important than it is in the MIS device and other technology-intensive industries. While 
our work focused on a single industry, future studies could consider VC investments across multiple industries, asking whether knowledge flow between disparate technologies could also be a boon to a VC's bottom line.

Likewise, because our work was interested in VCs as brokers and the firms in their portfolios, it is mostly silent on the ways the distribution of knowledge among portfolio firms impacts the firms themselves. Our work does suggest that such orchestration benefits favored firms and may negatively impact less-favored ones, but the research's principal value is the light it sheds on the role of VCs and what they can do to improve the performance of their portfolios. To that end, our findings could be applied to different settings in which firms manage relationships and knowledge sharing to benefit the bottom line. Future research may seek to understand the impact VC actions have on individual firms.

In summary, our research points to ways VCs can orchestrate knowledge among the firms in their portfolios to maximize profits. More than that, however, it also offers compelling evidence that VCs offer much more than capital. As VCs coordinate knowledge flows across firms, they don't just put more money in the bank. They may also spur technological progress and even advance entire industries.

\section{Read More}

Proven Entrepreneurs May Benefit Less From Partnering with Experienced VCs (https://eiexchange.com/content/292-research-insight-p roven-entrepreneurs-maybenefi?search=jon\%20eckhardt) 